\title{
TERTIARY DELIVERY MODES AND CONSTRUCTION INDUSTRY SECTOR HABITS, DO THEY MATCH YET ?
}

\author{
Linda Kestle ${ }^{1}$, Taija Puolitival ${ }^{2}$ \\ ${ }^{1}$ Unitec (New Zealand) \\ ${ }^{2}$ Unitec (New Zealand)
}

\begin{abstract}
Collaboration has become a buzzword, whether describing tertiary educational delivery modes or themes in industry related conferences, or touted by leaders in the construction industry sector. Educational organisations would not thrive without collaboration, and hence the term collegiality. Over the last two or so years Unitec has been developing and facilitating delivery modes involving blended learning, and project based learning for the undergraduate construction management and construction economics students. Teamwork and real-world learning is the norm. The question is, "How real is integrated collaboration in our construction industry as yet and does it yet match the focus of the Integrated design and construction management undergraduate course run at our institute?". How the course is delivered and assessed is compared with the findings and trends from the industry assignment, and presented in this paper. The findings suggest that whilst the majority of projects are still being run on the Design-Bid-Build basis of design then construct in that order, that there appears to be a slow but obvious shift toward several companies working collaboratively with clients, stakeholders, designers and contractors from the earliest stages of the projects.
\end{abstract}

Keywords: tertiary education, real world learning. construction industry, integrated collaboration.

\section{INTRODUCTION}

In the past, the teaching and learning methods in construction management reflected its origin, civil engineering, and were a combination of lecturing, tutorials, assignments and exams [1]. When communication and problem-solving skills have been listed among the most important skill areas in construction management, simultaneously research has found that construction management graduates are poorly equipped with these skills [2], [3]. The traditional lecturer-centred teaching and learning methods have not been responding to these requirements of the industry. Although the traditional teaching and learning model still exists in many tertiary institutes, many more have moved to student-centric methods including project and problem-based learning, team-based learning, and blended learning. Some have also successfully incorporated these methods with collaborative approaches across disciplines using methods such as the Integrated Project Delivery (IPD) approach [4], [5]. In this approach students from several different disciplines work together on a problem or a project. This approach is adopted from the construction industry where organisations work on a project in close collaboration sharing the responsibilities, risks and benefits. In some cases the students are studying in different institutes or even on different sides of the globe [6], [7].

The undergraduate integrated design and construction management (IDCM) course has been delivered for four years now, and aims to focus student learning on working collaboratively when in industry. The cohort is usually around 30+ students from diverse work and cultural backgrounds. Each year the students are predominantly working in the construction industry already in construction I project management companies as site managers, property development cadets, or construction management cadets. However there is now a growing number of International students annually with no NZ work/life experience, so they are seeking that experience in order to work in NZ's construction industry. Therefore, the cohort share their everyday experiences of working with people and projects in the industry, whether that is collaborative or more often confronting, competitive and traditional.

\section{METHODOLOGY}

This particular case-study is focused on and around the IDCM course, and involves the collaborative student-centred learning method. There is a clear aim and focus on best practice project design and 
construction management in terms of communication, when to involve the players (client, consultants, contractors, specialists) and the benefits of early involvement of everyone involved, or about to be, on the project. This is often referred to as $\mathrm{ECl}$ (early contractor involvement). What the students identified and discovered when undertaking the course assignment is described in the Findings and Discussion section of the paper. The assignment focused on establishing current construction project practices and whether and to what extent collaborative practice was already in evidence in the construction industry, as well as how the overall project was run from client briefing stage to the handover of the completed project to the client.

This Level 7 capstone undergraduate course comprises 4 learning outcomes that are focused on deriving client needs, managing the design process, integrating design and construction processes, evaluating the performance of the project and the project team. The course is studied in a block delivery mode being 4 full days (2x2days), with inter-block assessment work, online learnings, readings and regular online feedback to the students, as their assessment work progresses. On the course, students work in groups to apply their current work knowledge to set theoretical topics and real life construction project problems, using online literature sources and case studies provided. They then share their findings, with the other groups in the cohort, and challenge each others' findings and thinking. The students review and discuss and often challenge (from their on-site experiences), what are considered best practice project collaboration and integrated methods for project delivery, by published researchers. Best practice includes integrated delivery methods ranging from Design-Build projects (design and construction services provided by just the design-builder or the designcontractor), through to Alliances (a cooperative arrangement between two or more organisations that aids the selection of tenders and encourages cooperative relationships amongst construction project team members), to (IPD) Integrated Project Delivery - a collaborative alliance of people, systems and practices to optimize project results), and more recently the use of BIM (building information modelling /management) as an integrative process, that aligns very well with a collaborative approach on construction projects.

At the core of the course is the assignment, that runs throughout the course and assists the students make connections between the theory that they have learned, to the local practice in the New Zealand construction industry, establishing current project practices and whether, and to what extent, collaborative practice is already in evidence in the construction industry, as well as how the overall project is run from client briefing stage, through the design stages, the construction stages to the handover of the completed project to the client.

The students pair off and work collaboratively together to address the criteria and reach the staged goals. The pairs negotiate with each other, based on their access to construction companies, as to which company they will approach. There is a need to find either a company or a particular project and then establish how the company approaches their construction projects from the client briefing stage, how the projects are run from design through construction stages, right through to the handover of the completed project to the client, and includes a post-occupancy evaluation 6-12 months after project completion. Findings and relevant examples are written up by the students in a codified manner so that anonymity is maintained for the company and any of the projects involved. These real-world investigations are considered imperative from a learning perspective, by the course deliverers. The assignment also offers the students the opportunity to experience, and critically appraise the approaches and working practices of the specific construction industry sector that the focus company/project they have investigated, represents. Even more importantly, the students see first hand how the various companies work with stakeholders, clients, consultants, the on-site staff, and other related project personnel, and assess the levels of collaboration, or lack of it. In this manner, the students are then also required in the assignment, to critically evaluate how well the companies use collaborative methods, and what impact that might be having or have on their project delivery currently and/or on future projects. The student findings are described and discussed in relation to the assignment set for the IDCM course in 2016 , which follows in part:

\section{Assignment aim}

To prepare a report focussed on a particular NZ construction company, that shows rigorous investigation, relevant published research, applied and critical thinking, and clearly meets the criteria set.

Learning outcomes associated with this assignment

LO1 Analyse methods for deriving client needs - including evaluating stakeholder involvement 
LO2 Explore and analyse the management of the design process through to and including construction stages

LO3 Evaluate the rationale and strategies for integrating design and construction

LO4 Evaluate integrated design and construction performance

\section{Assessment requirements}

In pairs, identify a specific company for investigation. The company can be fulfilling any function within the construction industry, but should employ more than 15 staff and have been in operation for at least 5 years. If you are unsure of whether a company is suitable please check with your lecturer.

With written permission from the company and the personnel involved, collect data as required to answer the tasks as listed in the marking schedule. Data will come from talking with company personnel that you might already work with; company or project documents; and publicly available information on the company (for example, company or project websites). Provide actual examples from projects the company has completed or is completing, to underpin your findings, but do not name them in the submission.

Refer to relevant published research that offers comparisons or insights to the collected primary data. Include reviews or references for at least 5 sources.

Students were also asked to provide background information about the company, in an executive summary provided separately from the submission, and not published to provide anonymity yet also rigor to the submission. In addition, the students were tasked with exploring how BIM might be in use already in a company's practice as it fits well with integrated practice. However, neither the company, the projects nor BIM use in the focus company or project are discussed in this particular article.

\section{RESULTS AND DISCUSSION}

In the 2016 course delivery, there were 15 paired assignment submissions, and for the purposes of this paper, only two of the tasks' findings were reviewed as they specifically related to the topic of whether collaborative working approaches had been undertaken, how and to what extent. Those tasks were as follows:

1. How did the contractors and consultants work with and specifically involve the clients and/or stakeholders at various design and construction stages of projects undertaken by the selected company,

2. Was the company / project approach one that implemented an integrated delivery on the project(s), ie combining the thinking around design and construction management planning, and if so how did that play out.

On reviewing the submissions it quickly became evident that in this relatively small but useful sample, that whilst there is a shift toward an integrated delivery, and therefore collaborative approach on construction projects. The majority though, were still operating under the more traditional DBB (Design-Bid-Build) or segregated disciplinary approach (designers design, constructors construct and their roles follow each other in a straight line rather than an as integrated process from the get go.

The companies and projects involved were all commercial building projects, whether that was public utility (education, health, science), investment large scale residential properties, or infrastructure projects for example.

$50 \%$ of the companies did involve early and continuing clients/stakeholders involvement in terms of design and construction matters throughout the design and construction stages. 50\% did not, instead the contractors often only becoming involved once the design was set by the client and designers, or by involving the clients and stakeholders once they had won the contract and taken responsibility for all construction, risk and changes once the project was on-site.

$60 \%$ of the company/project approaches were either DBB (Design Bid Build) and a few were a hybrid of using traditional approaches with some integration but very little as yet. $40 \%$ were clearly taking an integrated delivery approach, and with significant success reportedly.

A brief summary follows of the overall relevant/pertinent paraphrased findings from the fully codified submissions to these two assignment tasks were 
- It could be perceived that an integrated approach was employed, due to input provided from several consultants and specialist contractors, as there is often no implementation that involves a complex set of relationships, which are evident when the design and build are fully integrated.

- Had the projects gone through an integrated approach right from the beginning, the way the work was done would have changed. Moving the design /construction decisions forward, means they are more effective and less costly.

- An integrated approach has ensured that the design programme within an accelerated construction programme has been structured so that tasks are delivered on time, and with less on-site issues thanks to the integrated and coordinated mechanisms for the works to progress steadily.

- Projects are structured at the pre-planning stage to focus on maximising value and reduce unnecessary waste at the construction stage.

- Practices undertaken on the project(s) has enabled a smooth operation of works on-site and a deep understanding of the project(s) and all the processes by the parties involved. All of which could not have been achieved on large scale projects, if a segregated approach had been taken. Segregated approaches tend to cause confusion between parties and lengthen the project duration.

- Responses to the pre-construction planning of the project in terms of how it impacted the build of the project was positive, because issues and problems that could have been a logistical nightmare had already been considered and averted.

In answer to the question of "How real is integrated collaboration in our construction industry as yet, and does it yet match the focus of the Integrated design and construction management undergraduate course run at our institute?" From this student cohort sample of 30 students in15 pairings, the answer is currently that progress toward collaborative integrated project delivery approaches is now becoming tangible in the industry, and that in turn supports the intent /aims of the delivery and assessment approaches being undertaken in the IDCM course, going forward as well.

\section{CONCLUSIONS}

As an academic and a researcher delivering courses that aim to reflect and align with the real-world of undertaking projects in the construction industry sector, there is a constant need to check that what is being delivered in qualifications such as the Bachelor of Construction degree is current whilst also being leading edge and forward-looking. The content, delivery mode and assessment regime has to prepare work-ready students for the industry, and at times lead and inspire the industry that the students are or will be working in. The 2016 IDCM assignment submissions provided a small snapshot sample of how the construction projects were being run from the briefing stage, through the design stages, construction to handover. More importantly, the assignment submissions identified the level and extent of collaborative integrated approaches being evidenced in the industry, which appears to be slowly but obviously shifting toward IPD, and away from the more traditional and segregated approaches.

\section{REFERENCES}

[1] J.E. Mills and D.F. Treagust, "Engineering education - Is problem-based or project-based learning the answer?", in Journal of the Australasian Association of Engineering Education, 2003. Retrieved from www.aaee.com.au/journal/2003/mills treagust03.pdf

[2] P. Love, J. Smith, J. Georgiou, D. Baccarini and P. Davis, "Building a symbiotic relationship between academia and industry: expectations and observations of construction management graduates", in Proceedings of the 28th annual conference of the Australasian Universities' Building Educators Association, pp. 109-116, 2003, Deakin University, Geelong, Victoria. Retrieved from http://dro.deakin.edu.au/view/DU:30009590

[3] M. Jaeger and D. Adair, "Communication simulation in construction management education: Evaluating learning effectiveness", in Australasian Journal of Engineering Education, 18(1), pp. 1-14, 2012, doi: 10.7158/D11-133.2012.18.1 
[4] J. MacDonald and J. Mills, "An IPD approach to construction education", in Australasian Journal of Construction Economics and Building, 13(2), pp. 93-103, 2013.

[5] H. Xie, E. Shim and K. Schmidt, "Integrated project delivery and team based learning in BIM education", in BIM Academic Symposium, 2017, Boston, Massachusetts.

[6] I. Kovacic, M. Flizmoser, D. Vasilescu and L. Oberwinter, "Challenges in teaching integrated BIM supported building design", in First International Conference of the BIM Academic Forum, September 13-15, 2016, Glasgow Caledonian University, Glasgow.

[7] R. Holland, S. Wing and D. Goldberg, "Interdisciplinary collaborative BIM studio", in BIM Academic Symposium, 2013, Washington, D.C. 